\title{
Protección animal: una reflexión constitucional
}

Margott Paucar Espinoza

Universidad Científica del Sur

margarettespinoza@gmail.com

\section{RESUMEN}

El presente estudio está constituido por una serie de breves reflexiones en torno al reconocimiento y protección jurídico-constitucional de la vida animal. Nos animan los avances que han ocurrido en los últimos años, lo cual no obsta para señalar que aún queda mucho por hacer en este campo, a nivel internacional y nacional. La cuestión no solo queda en el campo jurídico: también atraviesa el ámbito de la filosofía moral en relación con la toma de conciencia de la responsabilidad de los seres humanos con aquellos otros seres que habitan el mismo lugar.

\section{PALABRAS CLAVE}

Medio ambiente, bienestar animal, normas ambientales, protección constitucional, derecho ambiental.

\section{ABSTRACT}

The present study consists of a series of brief reflections regarding the recognition and legal protection of animal life. Though we applaud the advances that have been made in the last few years, they do not impede us from pointing out that there is still much work to be done on both the international and the national levels. The question is not limited to the judicial field, but intersects with moral philosophy in as much as it requires that human being accept their responsibility towards the other beings that inhabit the same environment.

\section{KEY WORDS}

Environment, animal welfare, environmental norms, animal protection, environmental law. 


\section{Estado de la cuestión}

La cuestión que nos planteamos, por un lado, se circunscribe a entender si las normas de protección de la vida animal deben configurarse a nivel constitucional o es suficiente su protección a niveles legales; $y$, por otro lado, si la normativa ambiental incluye la protección de la vida animal.

Hasta el momento, a nivel nacional, cada Estado ha regulado aspectos vinculados con la protección de los animales, específicamente de las llamadas especies protegidas. Sin embargo, no todas las Constituciones, en tanto normas supremas que gozan del máximo rango normativo, han configurado dicha protección, al menos expresamente, lo cual revela que la forma en que se ha venido estructurando jurídicamente este tema varía de país en país, en función de la importancia que ha tomado este tema en la vida política y social de un Estado en contrato.

\section{Un enfoque constitucional}

El siglo XX se ha caracterizado por los grandes avances a nivel constitucional e internacional en cuanto al reconocimiento y garantías de los derechos humanos. Aunque aún hay mucho por construir en cuanto a la efectividad de estos avances, existen otros retos que hoy llaman nuestra atención. La protección del medio ambiente y de la vida animal constituye sin duda una de las tareas pendientes más complejas. En este sentido, dar un paso más hacia una mayor presencia a nivel jurídico del mundo animal es una cuestión que no se puede soslayar y no solo porque se trate de un imperativo moral, sino también porque ya se trata de un asunto que atañe a la supervivencia de la propia vida en el planeta'.

En efecto, sea que forme parte de una norma de protección jurídica más amplia, como la que se brinda al medio ambiente, o constituya una norma de protección autónoma, la protección de la vida animal requiere definir ciertos lineamientos básicos que se concreten luego en políticas de acción para implementarse en el corto y mediano plazo, y sobre todo en el largo plazo. Ahora bien, consideramos que aunque la incorporación de la protección a nivel constitucional alcanza un mayor grado de protección, también es jurídicamente posible que a partir de las líneas básicas trazadas por normativa ambiental (constitucionalizadas) se pueda deducir de esta un marco de protección legal lo suficientemente vinculante como para que alcance una efectividad plena.

1 A modo de ejemplo, el último reporte del Ministerio del Ambiente indica que en 1999 vivían en territorio peruano 82.200 osos andinos. Sin embargo, respecto a los osos de anteojos solo quedaban vivos 2.000 a 2.400 , y se estimaba que estas cifras seguirían bajando. En Conexión Empresarial s. f.: 43. 
Por otro lado, podemos advertir que, en relación con la categoría jurídica que se le pretende atribuir a los animales con la finalidad de protegerlos, se ha suscitado una serie de debates en la comunidad jurídica, dado que la cuestión se torna complicada si intentamos atribuirle a los animales una categoría jurídica que ha sido creada para los seres humanos en su dimensión individual. Nos referimos a los denominados «derechos» fundamentales ${ }^{2}$ (derechos subjetivos), si analizamos desde el ámbito nacional; y los derechos humanos, si el análisis parte de una perspectiva internacional. Muchas razones jurídicas se esbozarían para no otorgarle dicha categoría jurídica a los seres no humanos; sin embargo, también es cierto que sí existen sobradas razones para no negarle una determinada forma de protección, sea a través de una categoría jurídica creada especialmente para ellos, o a través de una categoría jurídica que existiendo ya (bajo la denominación de derechos peculiares) velaría por su protección.

El presente artículo no pretende abarcar toda la gama de opciones jurídicas que sería posible esbozar respecto a la protección de la vida animal ${ }^{3}$, sino que, a partir de una observación del ordenamiento jurídico-constitucional de determinados países que han consagrado constitucionalmente dicha protección, trata de encontrar los argumentos comunes que fundamentan dichos preceptos constitucionales, los que finalmente podrían ser utilizados por otros países con el objeto de proteger la vida animal.

A continuación, veamos brevemente lo consagrado en algunos textos constitucionales:

La Constitución de Suiza ${ }^{4}$ ha incluido un capítulo entero referido a este punto. Este cambio constitucional tiene su base en la consideración por parte de la doctrina y de la clase política de las lagunas que existían en muchos ámbitos, entre ellos el ambiental. La doctrina y la clase política consideraron que no eran suficientes las reformas puntuales, sino una reforma total de la Ley Fundamental. De este modo, se han constitucionalizado contenidos normativos básicos, como dos principios de derecho ambiental: el principio de prevención y el de quien contamina paga. Se

2 Se usan las comillas porque la comunidad jurídica en general aún no ha admitido el término derecho para atribuir su titularidad de tipo subjetivo similar al de los seres humanos. Sin embargo, también debemos reconocer que algunos países sí han incluido dicha terminología para establecer una relación jurídica del Estado frente a la naturaleza y los animales. Tal es el caso de la Constitución de Ecuador, entre otras.

3 En el ámbito nos referimos a las obligaciones y responsabilidades que tiene todo Estado en el territorio que ocupa. Nos alejamos así de la calificación de cosa, que en el ámbito del derecho civil se implantó durante mucho tiempo en diversos países.

4 Texto que fue aprobado por referéndum del 18 de abril de 1999, y entró en vigor el 1 de enero de 2000. En http://www.bfm.admin.ch/content/dam/data/migration/publikationen/willkommen/willkommen-es.pdf 
incluye, además, el principio de desarrollo sostenible, lo cual significa un paso más hacia la ecologización del derecho constitucional.

Así, el artículo 80 de la Bundesverfassung establece la cláusula de protección de los animales, incluida en la sección 4: «Medio ambiente y ordenación del territorio». Este artículo establece varios aspectos relativos a la protección jurídica de los animales: El inciso 1 señala que la legislación sobre la protección de los animales es competencia de la Confederación. Asimismo, el inciso 2 establece que la legislación federal regulará: a) la custodia de los animales y los cuidados que deban dárseles; b) la experimentación con animales y los atentados a la integridad de animales vivos; c) la utilización de animales; d) la importación de animales y de los productos de origen animal; e) el comercio y transporte de animales; f) la matanza de animales. Asimismo, en el inciso 3 se señala que la ejecución de las prescripciones federales incumbe a los cantones, salvo que la ley reserve expresamente la competencia de la confederación.

Desde la misma perspectiva, pero haciendo énfasis en las responsabilidades y los deberes de las personas, la Ley Fundamental Alemana de 1949, hoy vigente con algunas modificaciones, se ocupa también de la protección de los animales. En el capítulo II, referido a la federación y los Estados regionales (Lánder), el artículo 20.a, modificado el 26 de julio de 2002, señala: «Consciente también de su responsabilidad hacia futuras generaciones, el Estado protege las bases natales de la vida y los animales dentro del marco del orden constitucional vía legislativa, y de acuerdo con la ley y la justicia, por el poder ejecutivo y judicial». En el mismo sentido, la última línea del inciso 20 del artículo 74 toca el tema de la protección de los animales ${ }^{5}$.

La pregunta que surge y a la vez nos cuestiona es si el texto constitucional puede establecer deberes de las personas. Ante esto, consideramos que los Parlamentos de estos países han llegado al convencimiento de que los cambios constitucionales deberían incorporar, como contrapeso a los derechos del individuo, la responsabilidad ya no solo del Estado, como órgano político, sino también de cada individuo en particular. De ese modo, la Constitución de Suiza introdujo después del catálogo de derechos fundamentales un precepto que resulta ser un mandato, ya que fija los deberes que deberá asumir cada persona ${ }^{6}$.

5 Medidas de protección en el comercio de productos alimenticios y otros artículos de consumo, objetos de necesidad, productos forrajeros, semillas y plantas agrícolas y forestales, protección de las plantas contra enfermedades y daños, así como protección de los animales. En http://ocw.um.es/cc.-juridicas/derecho-internacional-publico-1/ejercicios-proyectos-y-casos-1/ capitulo4/documento-20-constitucion-de-alemania.pdf

6 El artículo 6 de la Constitución suiza señala: «Toda persona es responsable de sí misma y asumirá conformemente a su capacidad tareas sociales y estatales». 
Por otro lado, instrumentos internacionales como el Tratado de Lisboa, en su artículo 21, acápite B, denominado «Modificaciones específicas», inserta un artículo con el texto del dispositivo del protocolo sobre la protección y el bienestar de los animales. Así pues, se añade el término pesca tras el término agricultura, Asimismo, las palabras e investigación se sustituyen por investigación y desarrollo tecnológico y espacio, y se añaden, además, las palabras como seres sensibles referido al bienestar de los animales.

La Constitución peruana no menciona nada sobre la protección animal, pero sí sobre la biodiversidad. Así, en el artículo 68, que es parte del capítulo II, «Del ambiente y los recursos naturales», se establece: «El Estado está obligado a promover la conservación de la diversidad biológica y de las áreas naturales protegidas».

Esto nos lleva a reflexionar acerca de la idea de reactivación de la ética de la responsabilidad. No apelar a esta idea nos hacer volver al pasado, a aquellas discusiones bizantinas que, si bien en su época eran hasta cierto punto comprensibles ${ }^{7}$, hoy, sin embargo, son menos justificables, teniendo en cuenta que día a día la ciencia certifica que los animales, unos en mayor medida que otros, son seres sensibles y merecen protección porque son parte de la biodiversidad.

Precisamente la protección de esa diversidad ha propiciado que el constituyente ecuatoriano dé un paso más allá en cuanto a la tutela jurídica de los recursos naturales. En efecto, Ecuador es el primer país del mundo que reconoce en su Constitución derechos inalienables a la naturaleza, y la convierte de esta manera en sujeto de derecho. La nueva Carta Magna ecuatoriana, aprobada en referendo, está inspirada en la filosofía del «buen vivir», que promueve la convivencia en armonía con la naturaleza o Pachamama, mediante el cuidado de la biodiversidad, de los recursos naturales, de la biosfera y del patrimonio natural ${ }^{8}$.

Aún más, la Constitución ecuatoriana consagra uno de sus capítulos a otorgar a la naturaleza derechos exigibles jurídicamente. Se considera a la naturaleza o Pachamama como aquel lugar donde se reproduce y realiza la vida; por lo tanto, tiene derecho a que se respete integralmente su existencia y el mantenimiento, así como la regeneración de sus ciclos vitales, estructura, funciones y procesos evolutivos ${ }^{9}$.

7 Como las que sostuvieron en su momento De las Casas y Ginés de Sepúlveda sobre la naturaleza de los indios y sobre si estos tienen o no derechos.

8 En http://www.biodiversidadla.org/Principal/Secciones/Noticias/Ecuador_la_Constitucion_mas_ verde

9 El artículo 71 de la Constitución, incluido en el capítulo denominado «Derechos de la naturaleza», establece precisamente tal exigencia. 
Tras conocerse la intención de consagrar derechos a la naturaleza en uno de los países más biodiversos del mundo, que cuenta con ecosistemas únicos como la selva amazónica o el archipiélago de las Galápagos, surgieron las preguntas: ¿Puede la naturaleza tener derechos? ¿A quién le corresponde reclamarlos?

Alberto Acosta, expresidente de la Asamblea Constituyente y uno de los promotores de los llamados derechos de la naturaleza, manifiesta: «En realidad, lo que se quería era hacer justicia a la naturaleza y reconocer que si la justicia social fue en el siglo XX el eje de las luchas, la justicia ambiental va a serlo en el siglo XXI». Según Acosta, el objetivo era «buscar un mecanismo para proteger la naturaleza y, a partir de esa visión, abrir la puerta a un nuevo régimen de desarrollo en Ecuador». En relación con la forma en que tales derechos pueden ser ejercidos, Acosta indica que la Constitución otorga a «toda persona, comunidad, pueblo o nacionalidad» la potestad de «exigir a la autoridad pública el cumplimiento de los derechos de la naturaleza» ${ }^{10}$. Finalmente, añade: «Ahora tenemos que construir la jurisprudencia adecuada para que la naturaleza pueda ser sujeto de derechos y no quede solo en un discurso lírico».

Pero, además del derecho a existir, en la nueva Constitución se le reconoce al medio natural el derecho a la restauración y se determina que «el Estado aplicará medidas de precaución y restricción para las actividades que puedan conducir a la extinción de especies, la destrucción de ecosistemas o la alteración permanente de los ciclos naturales» ${ }^{11}$. A continuación, dice que «se prohíbe la introducción de organismos y material orgánico e inorgánico que puedan alterar de manera definitiva el patrimonio genético nacional» ${ }^{12}$.

De un modo u otro, muchos sectores coinciden en señalar que la nueva Constitución ecuatoriana se ha convertido en un punto de inflexión en cuanto a la tutela de los recursos naturales y la búsqueda de un desarroIlo sustentable. Al menos jurídicamente, estos aspectos ya se encuentran debidamente enmarcados y las futuras leyes y políticas ambientales tendrán que delimitarse por lo expuesto en el texto constitucional. Lo que sucede es que también es cierto que existen aspectos que no han sido considerados, como el consentimiento expreso de las comunidades afectadas por cualquier proyecto de explotación de recursos naturales, entre otros, y que son reclamados precisamente por estos sectores sociales. Al

10 En http://news.bbc.co.uk/hi/spanish/latin_america/newsid_7646000/7646918.stm

11 Artículo 73 de la Constitución de Ecuador. En http://www.asambleanacional.gov.ec/documentos/constitucion_de_bolsillo.pdf

12 lbíd. 
respecto, Alberto Acosta señala: «No se pudo conseguir su aprobación, aunque hay la posibilidad de la consulta previa con una gran ventaja con respecto a lo que había antes, ya que la que realizará esa consulta previa será el Estado».

«Si bien somos el primer país del mundo que establece que la naturaleza tiene derechos, no estamos solos. Poco a poco se va gestando una conciencia de que sin naturaleza respetada no hay vida del ser humano asegurada», asegura Acosta.

Se observa, por ejemplo, que los países europeos con nivel de desarrollo humano alto han optado por incluir dentro de sus textos constitucionales, de forma expresa, determinados apartados en los que establece el marco jurídico de la protección que se les debe brindar a los animales. La protección en estos casos parte de la categoría jurídico-constitucional denominada responsabilidad jurídica del Estado. En sentido general, podemos señalar que estamos ante normas que constituyen mandatos, pero, a la par, en algunos de estos mismos artículos se hace referencia al deber que ser humano debe cumplir al respecto.

Por otro lado, hay que señalar que, a diferencia de aquellas medidas de protección que gozan los seres humanos (a los que se ha denominado derechos humanos o derechos fundamentales, según sea el caso), las medidas de protección a favor de los animales no han llegado a internacionalizarse con fuerza vinculante de aquellos. Lo que existe en la actualidad son declaraciones políticas que, de un modo u otro, postulan el reconocimiento de cierta protección jurídica. También es verdad que existen asociaciones y determinados grupos de presión que luchan por articular mecanismos de protección cada vez más efectivos y a la vez fomentar mayor conciencia en la población sobre este tema ${ }^{13}$.

Sea cual fuere la categoría jurídica adoptada para proteger la vida animal, lo real es que este tema ya está tocando las esferas de la norma constitucional, al menos en unos cuantos países. En efecto, estos Estados han incluido dentro de su normativa constitucional aspectos claves referidos al medio ambiente; otros incluso configuran una normativa relacionada

\footnotetext{
13 Diversos organismos y asociaciones que buscan concientizar a la población en diferentes países están activos en los últimos años. Así, por ejemplo, en una encuesta aplicada por el Fondo Internacional para la Protección de los Animales y su Hábitat, en China, en 2005 reveló que un $90 \%$ de los encuestados consideraba que tenía el deber moral de minimizar el sufrimiento de los animales y un $77 \%$ se manifestó a favor de promulgar leyes al respecto. Por otro lado, la Organización Mundial de Sanidad Animal (OIE) ha aceptado la necesidad de mejorar el bienestar de los animales de granja. En 2008 más de 400 participantes se reunieron en El Cairo durante la Segunda Conferencia Mundial sobre Bienestar Animal de la OIE, y propusieron una resolución en la que se señalan que la ética es tan importante como la ciencia al formular normas para el bienestar animal.
} 
con la protección de los animales. Lo que en todo caso tienen en común todas estas normas es que la fundamentación filosófica que les subyace es la preocupación moral y ética por el destino de los recursos naturales (la flora o la fauna). Se van elevando a categoría jurídica vinculante estas ideas que solamente se estudiaba en el ámbito de la filosofía moral y jurídica como aspiraciones del ser humano. Se va entendiendo que la protección en conjunto del medio ambiente y de los derechos del ser humano será lo que finalmente garantice no solo el ejercicio efectivo de los derechos humanos, sino la propia supervivencia de la biodiversidad existente. Aún queda mucho por construir a nivel jurídico, pero se observa que en algunos países este tema ya está encaminado. Esperamos que en otros, a través de la jurisprudencia o de la propia norma expresa, sea pronto una realidad. 


\section{REFERENCIAS BIBLIOGRÁFICAS}

ASAMBLEA CONSTITUYENTE (1949). Constitución de Alemania. En http:// ocw.um.es/cc.-juridicas/derecho-internacional-publico-1/ejercicios-proyectos-y-casos-1/capitulo4/documento-20-constitucion-de-alemania.pdf. Consultado el 8 de diciembre de 2011.

ASAMBLEA CONSTITUYENTE (2008). Constitución del Ecuador. En http:// www.asambleanacional.gov.ec/documentos/constitucion_de_bolsillo.pdf. Consultado el 8 de diciembre de 2011.

CONEXIÓN EMPRESARIAL (s. f.). «Áreas naturales protegidas. El paisaje mejor cuidado». En Conexión Empresarial, año 2, nro. 13.

CONSTITUCIÓN FEDERAL DE LA CONFEDERACIÓN SUIZA (1999). En http:// www.bfm.admin.ch/content/dam/data/migration/publikationen/willkommen/wiIlkommen-es.pdf. Consultado el 8 de diciembre de 2011.

FONDO INTERNACIONAL PARA LA PROTECCIÓN DE LOS ANIMALES Y SU HÁBITAT (s. f.). En http://www.alternativechannel.tv/communication-durable/users/ Fondo-Internacionalpara-Proteccion-Animales-y-Habitat/1465. Consultado el 8 de diciembre de 2011.

ORGANIZACIÓN MUNDIAL DE SANIDAD ANIMAL (s. f.). En http://www.oie.int/ es/. Consultado el 8 de diciembre de 2011.

Recibido: Marzo de 2012.

Aceptado: Mayo de 2012. 